\title{
A study on the stability of urinary free catecholamines and free methyl-derivatives at different $\mathrm{pH}$, temperature and time of storage
}

\author{
Norman B. Roberts*, Gerald Higgins and \\ Mansour Sargazi
}

Department of Clinical Biochemistry, The Royal Liverpool and Broadgreen University Hospitals, Liverpool, UK

\begin{abstract}
Bakground: The goal of our study was to test the relative stability of urine, unconjugated, free catecholamines and the methyl derivatives. We measured the change in concentrations in commercially available urines after storage at various $\mathrm{pH}$ values, temperatures and time, from days up to 10 weeks. Methods: Samples of commercial control urines were adjusted to $\mathrm{pH} 2.0,4.0,6.0$ and 8.0 and aliquots stored at ambient temperature $\left(20-26^{\circ} \mathrm{C}\right), 4^{\circ} \mathrm{C}$ and $-18^{\circ} \mathrm{C}$. The free catecholamines (cats) and the free methyl derivatives (mets) were measured after 1, 2, 3 and 6 days and 1,2, 3 and 10 weeks using the automated sample trace enrichment dialysis (ASTED) procedure with reversed phase ion pair high performance liquid chromatography (HPLC) and coulometric detection.
\end{abstract}

Results: Free catecholamines were relatively stable, with $<15 \%$ loss of concentration, when stored at $\mathrm{pH} 6.0$ or less for at least 4 days and up to 10 weeks at $\mathrm{pH} 2.0$ at either $4^{\circ} \mathrm{C}$ or $-18^{\circ} \mathrm{C}$. At $\mathrm{pH} 8.0$, the concentration fell to $<60 \%$ after $48 \mathrm{~h}$ and at a $\mathrm{pH}$ of 6.0 or 8.0 , up to $90 \%$ was lost within the first week at $4^{\circ} \mathrm{C}$ and $25^{\circ} \mathrm{C}$. More than $40 \%$ of free normetadrenaline and metadrenaline were lost after 1-2 weeks when stored at $20-25^{\circ} \mathrm{C}$ and $\mathrm{pH}$ 8.0. After 10 weeks at $\mathrm{pH} 4.0,6.0$ and 8.0, up to $90 \%$ loss was observed at $25^{\circ} \mathrm{C}$. Free cats were stable at $\mathrm{pH} 2.0$ and 4.0 at $-18^{\circ} \mathrm{C}$ and the free mets were stable at $-18^{\circ} \mathrm{C}$ over the entire time period studied and at all $\mathrm{pHs}$.

Conclusions: In the analysis of free catecholamine and the free methyl derivatives, urine samples should be acidified to a $\mathrm{pH}$ range $2.0-3.0$ to ensure stability and hence the correct analysis.

Clin Chem Lab Med 2010;48:81-7.

\footnotetext{
*Corresponding author: Norman B. Roberts, The Department of Clinical Biochemistry, The Royal Liverpool and Broadgreen University Hospitals, Liverpool, UK

E-mail: n.b.roberts@ liverpool.ac.uk

Received June 18, 2009; accepted September 20, 2009;

previously published online November 25, 2009
}

Keywords: free catecholamines; methylated derivatives; stability; urine.

\section{Introduction}

The measurement of the free (non-conjugated) or total (combination of the free and conjugated) individual catecholamines (cats) and/or the total individual methylated derivatives (mets) is well established for the detection of tumours that secrete catecholamines in urine (1-3) or in plasma (4). Recently, measurement with on line clean up [automated sample trace enrichment dialysis (ASTED)] and ion pair based separation of the free methylated compounds was suggested to be at least as good as total individual mets and/ or free unconjugated parent (cats), or possibly a better alternative (5). Over the past several years, we have successfully used the ASTED procedure for the measurement of both the free parent and methylated derivatives. We have always observed good concordance between the two; if one is increased the other is also increased (6). However, cases that break the rules can always be found. For example, normal cats raised mets and normal cats and mets with increased vanillylmandelic acid (VMA) (7). As many analytes as possible are used to catch all the possible scenarios, although for the diagnosis of phaechromocytoma, urinary free metadrenalines have been shown to demonstrate superior clinical sensitivity over plasma or urinary catecholamines or urinary VMA (8). Also, we have confirmed the importance and benefit of simultaneous measurement of dopamine, which can be increased in $\sim 3 \%$ of urines from adults with catecholamine secreting tumours $(9,10)$. A recent review on tumours that secrete catecholamines suggested that metadrenalines in urine or plasma are the most likely to be abnormal (11). However, this is clearly not correct in patients with tumours that secrete dopamine only, or its metabolites $(9,10)$.

The underlying problem for all these analyses is the integrity/dependability of the sample. Catecholamines are sensitive to oxidation, particularly at greater than neutral $\mathrm{pHs}$ where the well described adenochrome-like compounds are formed from adrenaline and noradrenaline, and dopachrome from dopamine (12). Thus, it is imperative that low $\mathrm{pHs}$ of $<4.0$, and preferably $<3.0$ are used, along with an antioxidant for long-term storage. A major confounding variable in the diagnostic value of urinary free cats is changes due to oxidative decay; a loss of as little as $20 \%-30 \%$ can result in abnormal values being reported as normal. This is another 
Table 1 Analytical characteristics of free catecholamines and free methyl derivatives in commercial quality control urine.

\begin{tabular}{clllll}
\hline Analyte, nmol/L & Noradrenaline & Adrenaline & Normetadrenaline & Metadrenaline & Dopamine \\
\hline Lypho 1 & 250 & 74 & 1385 & 362 & 552 \\
& $(210-290)$ & $(54-94)$ & $(1125-1645)$ & $(262-462)$ & $752-652)$ \\
& $7.0 \%$ & $9.6 \%$ & $8.3 \%$ & $787 \%$ & 3124 \\
Lypho 2 & 1158 & 466 & $(6478-9278)$ & $(2210-3490)$ & $(2624-3624)$ \\
& $(1028-1278)$ & $(386-546)$ & $7.3 \%$ & $9 \%$ & $5.7 \%$ \\
BioRad HPLC & $4.8 \%$ & $6.7 \%$ & & 598 & 601 \\
Level 1 & 284 & 93 & 1911 & $(446-750)$ & $(451-751)$ \\
Level 2 & $(213-355)$ & $(60-126)$ & $(1420-2402)$ & 3093 & 3461 \\
& 1229 & 502 & 8518 & $(2459-3726)$ & $(2612-4310)$ \\
\hline
\end{tabular}

Lypho 1 and 2 values are nmol/L as mean and in parentheses ( ) ranges observed over a 6-month period $(\mathrm{n}=20)$; the $\mathrm{CV} \%$ quoted is between batch precision analysis. The BioRad (Lypho) HPLC values are those given by the manufacturer showing the target mean and range of acceptable results in ( ) and indicate similar values to those analysed. The slightly lower values for the Lypho 1 normetadrenaline and metadrenaline probaly related to the amount of endogenous sulpho complex not measured.

reason why measurement of mets is preferred, as they are apparently much less likely to degrade at neutral $\mathrm{pH}$. A recent study (13) of stability over 7 days indicated that the parent catecholamines are relatively unstable in unacidified urines, losing more than $50 \%$ of their initial concentration. However, total (free plus conjugated) methyl compounds remained stable over the 7 days. These findings have been confirmed several times, in particular for the non-methylated and unconjugated parent compounds $(14,15)$. However, from our own experience in the measurement of the unconjugated free compounds, it is often observed that low cats are present with low mets in unacidified urine with $\mathrm{pHs}$ up to $\mathrm{pH}$ 8.0. This finding suggests that free mets are not as stable as predicted.

If the assay of the free compounds, particularly free mets becomes more widespread, it is important to have good analytical data on their relative stabilities in urine. Our goal was to reassess the stability in urine of both unconjugated free and methylated compounds, over a $\mathrm{pH}$ range of 2.0, 4.0, 6.0 and 8.0 , temperatures of $-18^{\circ} \mathrm{C}, 4^{\circ} \mathrm{C}$ and room temperature $\left(20-26^{\circ} \mathrm{C}\right.$ ), and over a long period of time (days up to 10 weeks). We chose a reference urine material so that we could be certain of the concentrations (added in as the free metabolites) and little variation in antioxidants such as vitamin $\mathrm{C}$ that could affect stability.

\section{Materials and methods}

All chemicals used were of Analar grade and solutions were prepared using doubly deionised water (Ultra Q, Elga Products, High Wycombe, UK).

Urine Lypho I and II (Lyphocheck, Urine Quality Controls, BioRad Laboratories, Hemel Hempstead, UK) were used for comparative purposes, with the stated and laboratory measured concentrations for the relevant analytes shown in Table 1. The commercial urine samples were spiked with unconjugated mets. The values quoted in Table 1 for the BioRad high performance liquid chromatography (HPLC) are total methylcated derivatives and include any residual urine derivative compounds; hence the slight discrep- ancy between the stated values and our measured concentrations. Aliquots of these urines were prepared at various $\mathrm{pH}$ values 2.0, 4.0, 6.0 and 8.0 by the addition of small amounts of $4 \mathrm{M}$ sulphuric acid $\left(\mathrm{H}_{2} \mathrm{SO}_{4}\right)$, or $4 \mathrm{M}$ sodium hydroxide $(\mathrm{NaOH})$. The amounts added did not cause any significant dilutional effects. However, to avoid any misinterpretation due to dilution, data were expressed as percent of the analysis obtained at day 0 . The samples were stored at ambient room temperature $\left(20-26^{\circ} \mathrm{C}\right), 4^{\circ} \mathrm{C}$ and $-18^{\circ} \mathrm{C}$ and analysed on days $0,2,4$, and 6 and weeks $1,2,3$ and 10 .

Separate aliquots were measured for the free catecholamines, noradrenaline, adrenaline and dopamine, and the free methyl derivatives (mets) normetadrenaline and metadrenaline. The analysis (16) of all these separate compounds was achieved using ion pair HPLC on a $15 \mathrm{~cm}$ Spherisorb 5 octadodecyl silanyl (ODS) (2) after automated sample preparation (ASTED) and detection by coulometry (Coulochem, ESA Analytical Ltd., Aylesbury, UK).

The actual analytical between batch imprecision for each analyte in Table 1 was between $4.8 \%$ and $11 \%$, with an average of $\sim 7.5 \%$. A reduction in concentration was regarded as significant if the measured change was $>15 \%$, determined by taking two times the average CV of $7.5 \%$ as a cut-off threshold for significant change. The data are presented graphically with individual data points to show changes at the different times and temperatures.

\section{Results}

The free catecholamines were relatively stable at $\mathrm{pH} 6.0$ or less for at least 4 days, with less than a $15 \%$ decrease in concentration as shown in Figures 1-3 (urine Lypho 1 and 2 ). However, at $\mathrm{pH} 8.0$, the measured concentration fell to $<60 \%$ of starting values after $48 \mathrm{~h}$. Even when stored at $-18^{\circ} \mathrm{C}$ at high $\mathrm{pH}$, the change in concentration was still significant with more than $60 \%$ loss after 4 days. Studies with Lypho 2 urine that contained higher amounts, the free catecholamines degraded in similar fashion after 2-3 days at ambient temperature and $\mathrm{pH}$ 8.0. Following 1 week of storage at either $\mathrm{pH} 6.0$ and 8.0, all the free analyte was lost. There was no significant change in the measured concentration of free normetadrenaline and metadrenaline over a 7day period at any $\mathrm{pH}$ when stored at $4^{\circ} \mathrm{C}$ or $-18^{\circ} \mathrm{C}$. However, 
Lypho 1

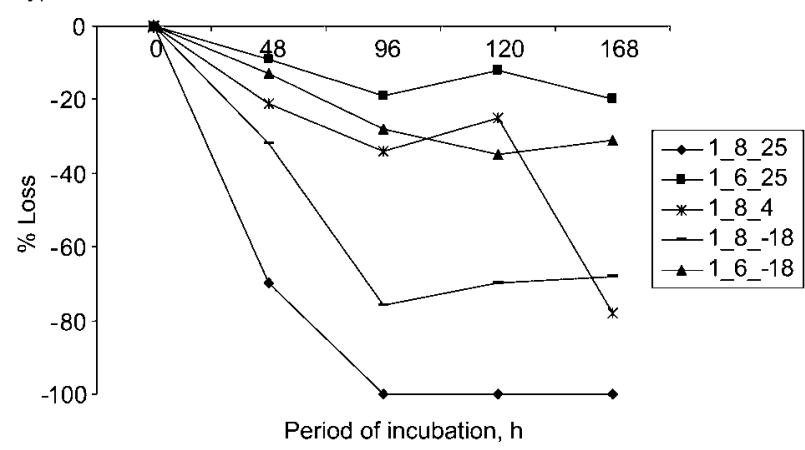

Lypho 2

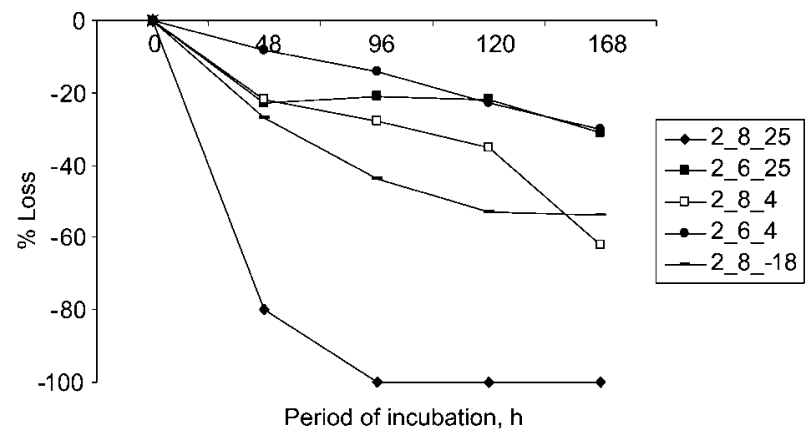

Figure 1 Change in concentration of noradrenaline in urine Lypho 1 and Lypho 2 after storage up to 7 days at various temperatures $\left(25^{\circ} \mathrm{C}, 4^{\circ} \mathrm{C}\right.$ and $\left.-18^{\circ} \mathrm{C}\right)$.

Samples kept at $\mathrm{pH} 2.0$ or 4.0 and temperatures of $4^{\circ} \mathrm{C}$ or $-18^{\circ} \mathrm{C}$ showed no significant change in the measured concentration.

when stored at $\mathrm{pH} 8.0$ and ambient/room temperature $\left(25^{\circ} \mathrm{C}\right)$, normetadrenaline showed a decrease in concentration of up to $20 \%$ after 7 days, while metadrenaline showed no change (data not shown).

Studies of longer storage times (Figure 4) showed that free catecholamines were stable at $\mathrm{pH} 2.0$ and $\mathrm{pH} 4.0$ for up to 10 weeks at either $4^{\circ} \mathrm{C}$ or $-18^{\circ} \mathrm{C}$. However, at $\mathrm{pH} 6.0$ and $8.0,90 \%$ was lost within the first week at $4^{\circ} \mathrm{C}$ or $25^{\circ} \mathrm{C}$. Marked loss was also observed at $\mathrm{pH} 4.0$ when stored at $25^{\circ} \mathrm{C}$ for up to 10 weeks.

Free normetadrenaline (Figure 5) showed more than $90 \%$ loss at $\mathrm{pH} 8.0$ when stored at $25^{\circ} \mathrm{C}$ for 2 weeks, and from $40 \%$ to $>90 \%$ loss at $20^{\circ} \mathrm{C}$ after 10 weeks at $\mathrm{pH} 4.0,6.0$ or 8.0. Free metadrenaline (Figure 6) showed more than $75 \%$ loss after 10 weeks at $\mathrm{pH} 4.0,6.0$ or 8.0 when stored at $25^{\circ} \mathrm{C}$.

Fee normetadrenaline and metadrenaline in both Lypho 1 and 2 were stable when stored at $-18^{\circ} \mathrm{C}$ over the entire time period and at all $\mathrm{pH}$ values.

\section{Discussion}

This study showed that free catecholamines are relatively stable over several days and a range of concentrations if the urine is kept at $4^{\circ} \mathrm{C}$ and at $\mathrm{pH} 6.0$ or less. This has also been observed (17) with urine collected in the hospital ward with- out acid preservative and $\mathrm{pH}$ values up to 7.0, as long as samples were delivered to the laboratory and analysed immediately or acidified and stored at $-18^{\circ} \mathrm{C}$ prior to analysis. To ensure stability of free parent and methylated catecholamines, we always recommend collecting urine in bottles containing acid. Following receipt of the sample in the laboratory, the urine $\mathrm{pH}$ is checked and acidified if necessary to at least a $\mathrm{pH}$ of 3.0 and stored at $-18^{\circ} \mathrm{C}$ before analysis within 1-2 weeks. The dependability of sample integrity is probably one of the confounding variables in the diagnostic value of free catecholamines, and is one of the major reasons why measurement of the mets is preferred; they are much less likely to degrade at neutral $\mathrm{pH}$. However, we have now shown that the free mets are also prone to degradation if maintained at high $\mathrm{pH}$ and room temperature. Thus, precaution must be taken to avoid loss of these analytes from oxidation. It may of course be that the sulphated forms of the mets are themselves more stable with long-term storage regardless of $\mathrm{pH}$, although no studies on this aspect have been reported.

Studies with individual human samples, as opposed to commercially available control urine, could be confounded by the presence of antioxidants such as vitamin $\mathrm{C}$, citric acid and other amino acids that might act as oxidative scavengers. This probably explains why the change in urine cats can be minimal for up to 2 days, even at room temperature (13). This latter study showed that catecholamines were stable at $\mathrm{pH} 7.0$ and $4^{\circ} \mathrm{C}$, whereas after 7 days at room temperature
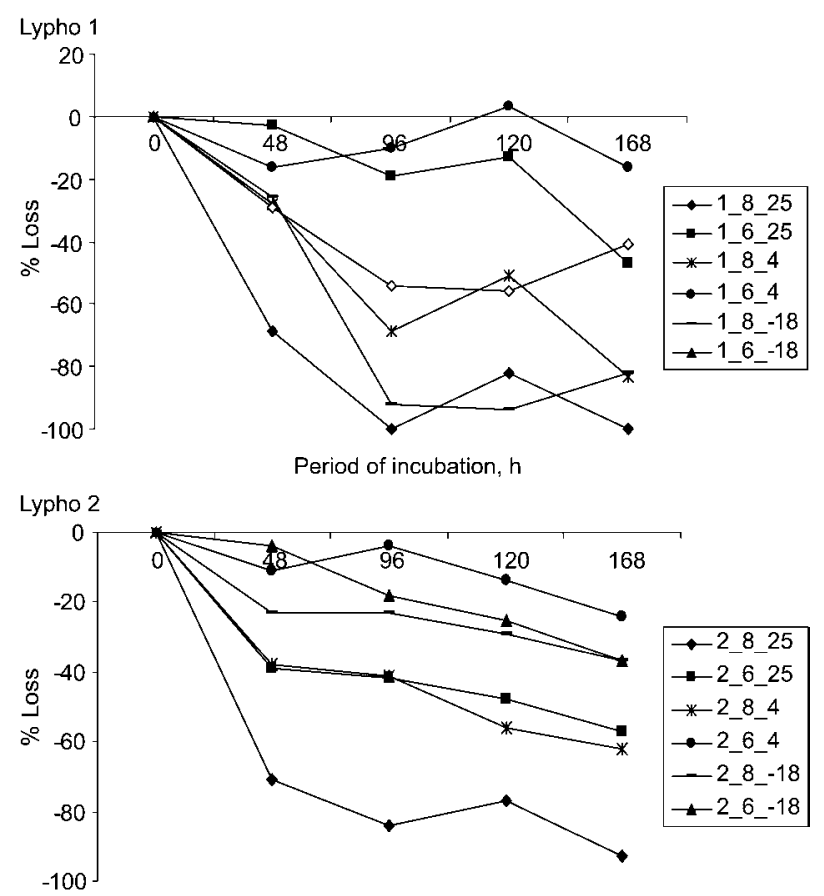

Period of incubation, $\mathrm{h}$

Figure 2 Change in concentration of adrenaline in urine Lypho 1 and Lypho 2 after storage for up to 7 days at various temperatures $25^{\circ} \mathrm{C}, 4^{\circ} \mathrm{C}$ and $-18^{\circ} \mathrm{C}$.

Samples kept at pH 2.0 or 4.0 and temperatures of $4^{\circ} \mathrm{C}$ or $-18^{\circ} \mathrm{C}$ showed no significant change in the measured concentration. 


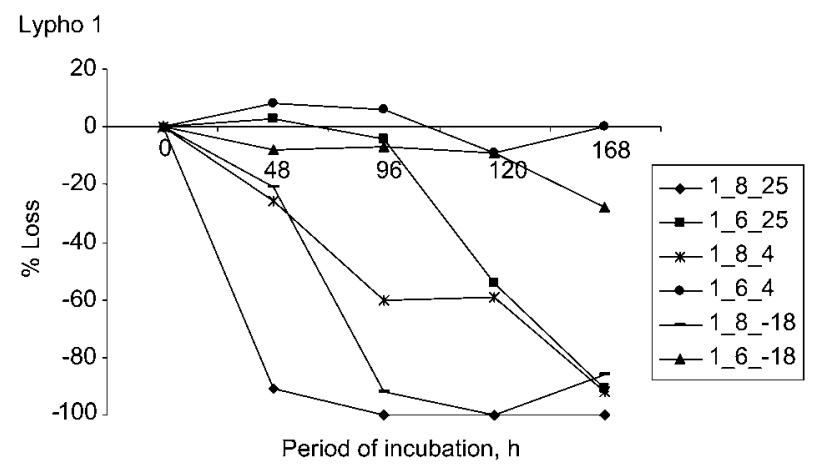

Lypho 2

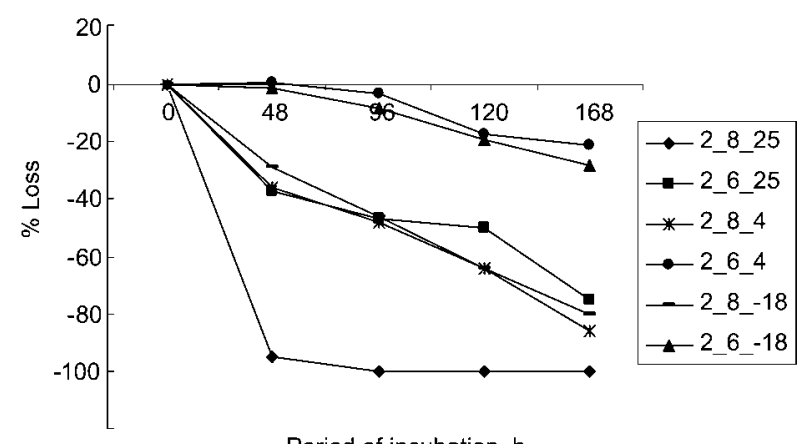

Period of incubation, h

Figure 3 Change in concentration of dopamine in urine Lypho 1 and Lypho 2 after storage for up to 7 days at various temperatures $25^{\circ} \mathrm{C}, 4^{\circ} \mathrm{C}$ and $-18^{\circ} \mathrm{C}$.

Samples kept at pH 2.0 or 4.0 and temperatures of $4^{\circ} \mathrm{C}$ or $-18^{\circ} \mathrm{C}$ showed no significant change in the measured concentration.

$\left(20-25^{\circ} \mathrm{C}\right)$ a loss in concentrations of up to $30 \%$ was reported. The free catecholamines were relatively stable for a few days at $\mathrm{pH} 8.0$, but only if kept at $4^{\circ} \mathrm{C}$ (13). At the extreme $\mathrm{pH}$ of 10.0, catecholamines degraded within a few hours. Interestingly, at a $\mathrm{pH}$ of $<1.0$, measured free catecholamines increased up to $50 \%$ after 7 days due to hydrolysis of the conjugated forms (13). Also, over-acidification can cause urine to become extremely dark in appearance, resulting in analytical problems due to extraneous peaks on the chromatogram. Therefore, it is important not to acidify to a $\mathrm{pH}$ of $<2.0$.

A recent review (18) on the analysis of urinary catecholamines concluded that any strong acid could be used as long as the final $\mathrm{pH}$ was 3.5 or less. However, for assays using the ASTED procedure, $\mathrm{H}_{2} \mathrm{SO}_{4}$ is recommended as preservative because this acid, unlike hydrochloric acid is nonoxidising (16). To reduce the risk to patients posed by the presence of acid in urine collection bottles, the addition of sand (1 g Sigma grade for a 24-h collection) has been used to maintain a low urine $\mathrm{pH}$ without risks of acid leakage (18). An alternative to the use of a strong acid preservative was the use of formate buffer (19) to maintain the urine $\mathrm{pH}$ at $\sim 3.5$. Urine catecholamines preserved in this way were as stable as those in acid preserved urines when stored at $-80^{\circ} \mathrm{C}$. However, decrease in concentration of up to $40 \%$ was observed after storage for 8 weeks at $4^{\circ} \mathrm{C}$. Alternative sta- bilising agents such as EDTA or sodium bisulphite could be used without any loss of activity, as long as samples were collected and then stored immediately at $-18^{\circ} \mathrm{C}$ before analyis (13). The effect of physiological temperature should also not be ignored as urine may reside in the bladder at elevated $\mathrm{pH}$ and $37^{\circ} \mathrm{C}$ for several hours. Under these conditions, instability may be increased particularly for the catecholamines (20). These authors therefore recommended that during urine collection for measurement of catecholamines, the bladder should be emptied every $3 \mathrm{~h}$, if possible.

Because of the problems associated with the collection of urine into acid, there is increasing support for measurement of methylated catecholamine derivatives as the most appropriate - 'best test' - for catecholamine secreting tumours. However, we advise that both types of compounds be measured, especially considering that the diagnostic features of these tumours are the excess production of active biogenic amines, and not the methyl derivatives (21). However, a recent review on the function and metabolism indicated that the free methylated compounds may show some physiological function (22), whereas sulpho conjugation (the major urine metabolite) results in complete deactivation of the catechols (23). Of interest is that a significant proportion of methylation can occur within the adrenal gland and the tumours themselves, and it is possible to relate the amount of methyl derivatives that are secreted to tumour size $(8,24)$. These arguments support the view that the free species are the most physiologically relevant and therefore the most appropriate analytical target.

The value of measurements in plasma (3) of the free nonand methylated components really depends on improvements in analytical performance, appropriateness of sample collection and good renal function. If these conditions can be satisfied, such assays will have marked impact in terms of convenience to both the patient and laboratory. However, at this time most laboratories still use urine collection as the basis in the investigation of tumours that secrete catecholamines. Unfortunately, whatever test is used, it is still possible that both misleading laboratory results combined with clinical investigation including CT and magnetic resonance imaging (MRI) may miss the tumour or result in the wrong diagnosis, as shown in a recent review on the diagnosis of phaechromocytoma (25). The patient's age may also be a confounding variable (26). In spite of these issues, a recent study (27) suggested that plasma free metanephrines are most likely to confirm the presence of a catecholamine secreting tumour (being up to $100 \times$ normal concentrations), rather than urine mets, cats or HMMA (4-hydroxy-3-methoxy mandelic acid). Unfortunately, the concentrations of the separate mets are still relatively low, requiring up to $1 \mathrm{~mL}$ of plasma for analysis by HPLC, and also can be raised up to 10 times normal in patients with renal failure. In addition, the analytical performance at low concentrations can be poor, as seen in our own experience of an automated plasma catecholamine method that used electrochemical detection where the analytical performance was unpredictable (28). However, newly developed liquid chromatography-mass spectrometry 
A

$$
\text { Lypho } 1
$$

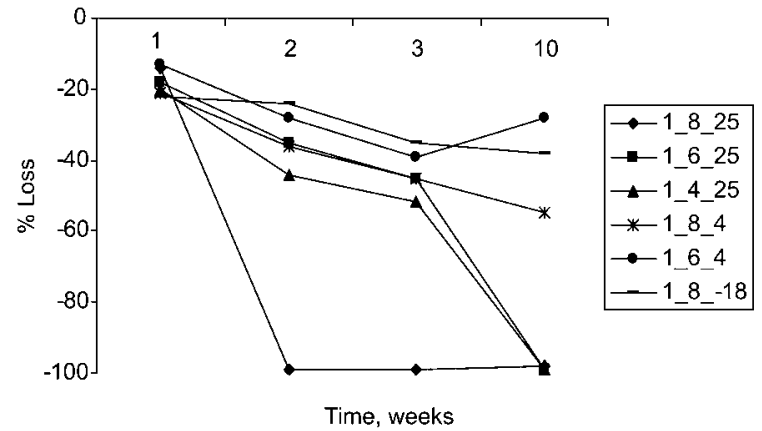

Lypho 2

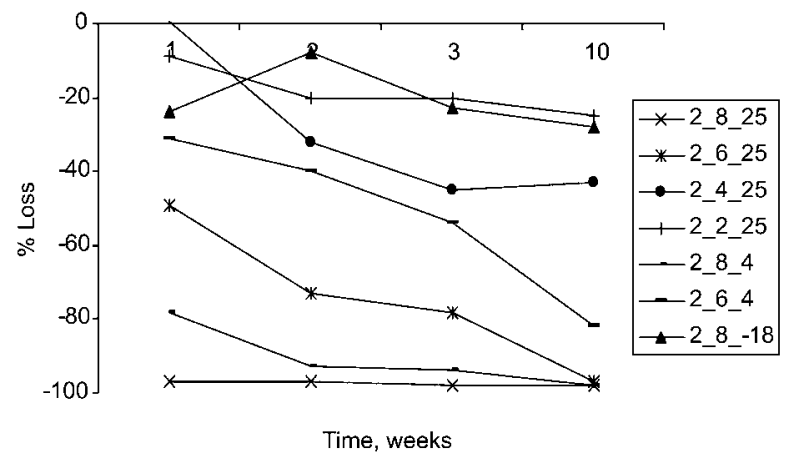

C

Lypho 1

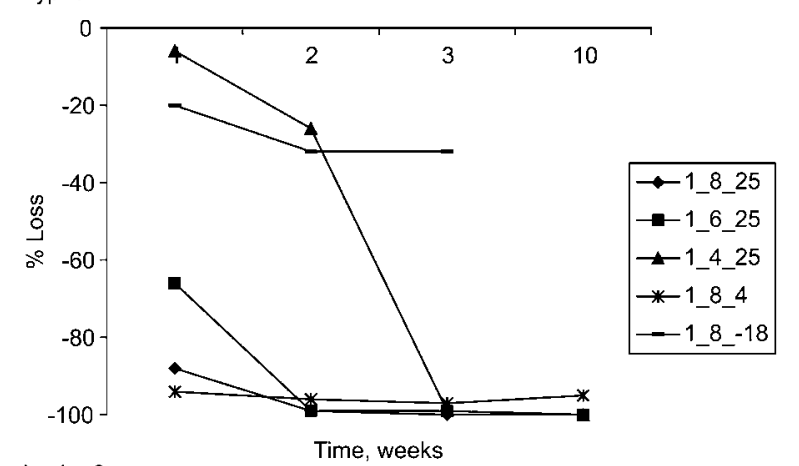

Lypho 2

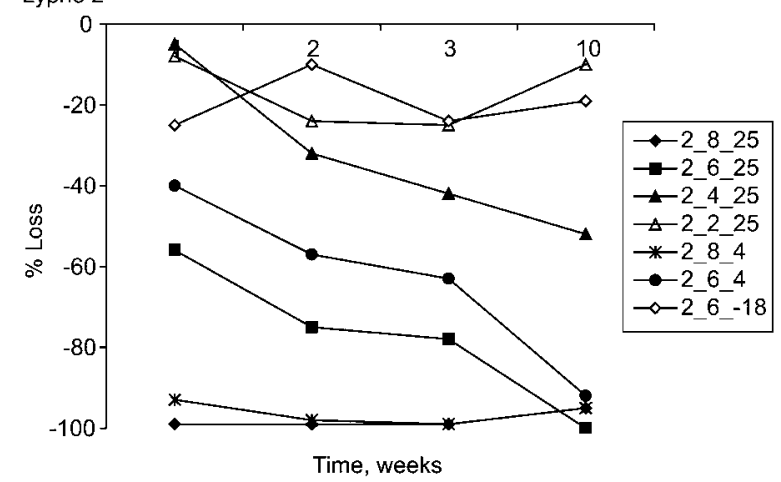

Figure 4 Change in concentration of (A) noradrenaline, (B) adrenaline and (C) dopamine in urine Lypho 1 and Lypho 2 after storage from 1 to 10 weeks at various $\mathrm{pH}$ values and temperatures of $25^{\circ} \mathrm{C}, 4^{\circ} \mathrm{C}$ or $-18^{\circ} \mathrm{C}$.

Samples kept at pH 2.0 or 4.0 and temperatures of $4^{\circ} \mathrm{C}$ and $-18^{\circ} \mathrm{C}$ showed no significant change in the measured concentration. 

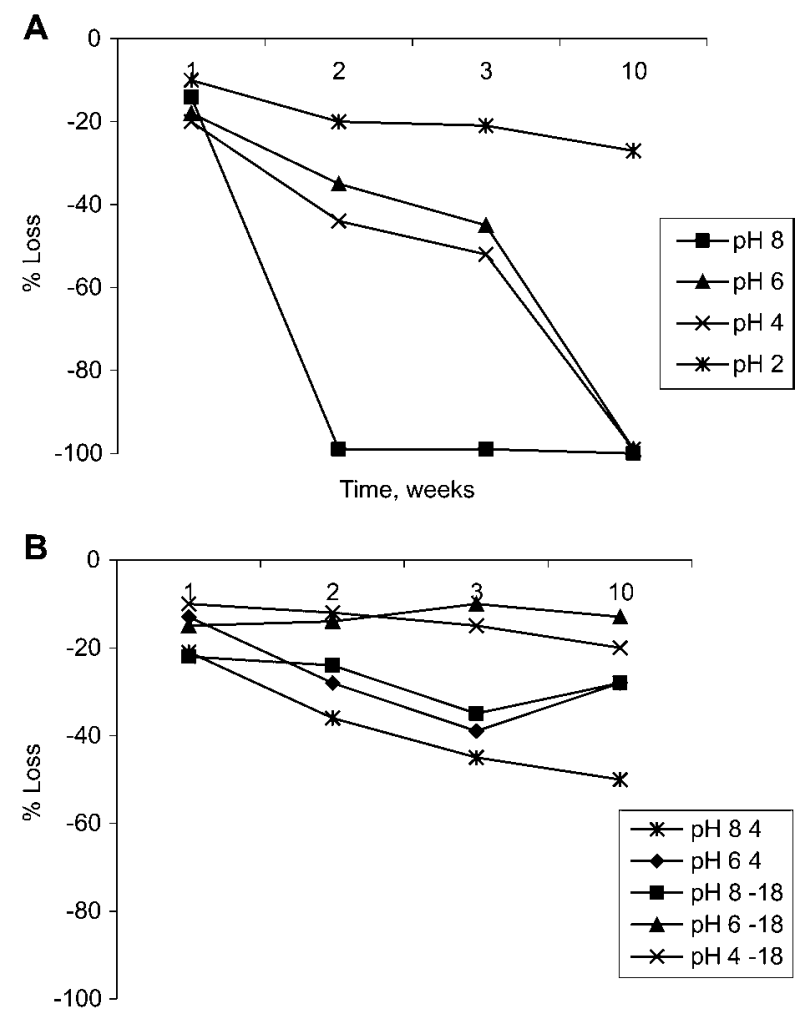

Time, weeks

Figure 5 Change in concentration of (A) normetadrenaline at $25^{\circ} \mathrm{C}$ and (B) normetadrenaline at $4^{\circ} \mathrm{C}$ in Lypho 1 after storage from 1 to 10 weeks.

Lypho 2 showed very similar trends, but data are not shown. Samples kept at $\mathrm{pH} 2.0$ and or 4.0 and temperatures of $4^{\circ} \mathrm{C}$ and $-18^{\circ} \mathrm{C}$ showed no significant change in the measured concentration.

(LCMS) techniques require less sample (50-100 $\mu \mathrm{L})$ and seem to provide good analytical performance both at normal and increased values (29). Nevertheless, increased plasma metanephrines may be misleading in up to $20 \%$ of patients (25). Indeed, a recent review concluded that plasma and urine free metanephrines should be considered complementary rather than mutually exclusive (30). Thus, it is important that the analytical pitfalls, in particular the instability of the analytes and the need for appropriate collection, are clearly understood.

In conclusion, we confirmed that free catecholamines can be stable in urine at a $\mathrm{pH}$ of 6.0 (i.e., similar to an unacidified urine collection) for short periods of time such as 2-3 days, and particularly if stored at $4^{\circ} \mathrm{C}$ or $-18^{\circ} \mathrm{C}$. The free methylated derivatives are stable for up to 2-3 weeks if stored under similar conditions, but do degrade if urine is kept at a high $\mathrm{pH}$ of up to 8.0 for several days/weeks, particularly if left at room temperature. Therefore, to avoid any problems with analyte instability, it is strongly recommended that $24 \mathrm{~h}$ urines be collected into acid, or to acidify freshly collected samples to between $\mathrm{pH} 2.0$ and 3.0 and then store at $-18^{\circ} \mathrm{C}$ prior to analysis. Care must also be taken not to overacidify samples to a $\mathrm{pH}$ of $<2.0$ to avoid hydrolysis of the conju-
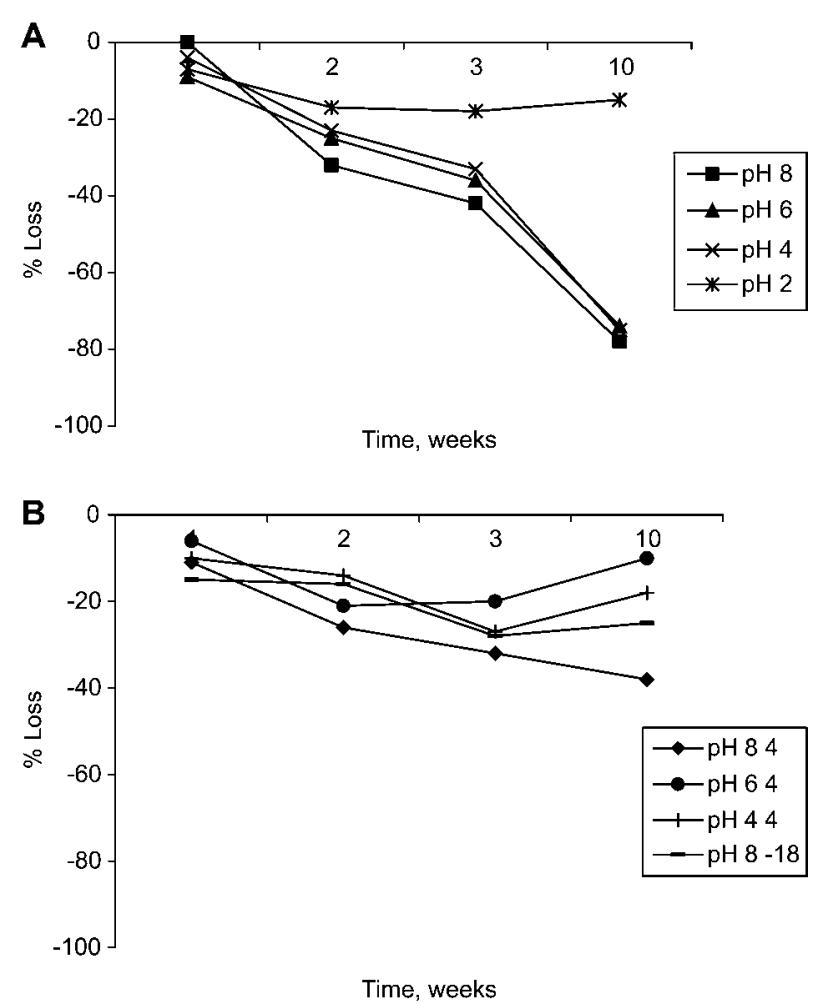

Figure 6 Change in concentration of (A) metadrenaline at $25^{\circ} \mathrm{C}$ and (B) metadrenaline at $4^{\circ} \mathrm{C}$ and $-18^{\circ} \mathrm{C}$ in Lypho 1 after storage from 1 to 10 weeks.

Lypho 2 showed very similar trends, but data are not shown. Samples kept at $\mathrm{pH} 2.0$ or 4.0 and temperatures of $4^{\circ} \mathrm{C}$ and $-18^{\circ} \mathrm{C}$ showed no significant change in the measured concentration.

gated compounds. Our view is in agreement with that of others $(5,8)$ that analysis of both the free cats, and including dopamine and free mets will provide the most diagnostically useful profile.

\section{Conflict of interest statement}

Authors' conflict of interest disclosure: The authors stated that there are no conflicts of interest regarding the publication of this article.

Research funding: None declared.

Employment or leadership: None declared.

Honorarium: None declared.

\section{References}

1. Gerlo EA, Sevens C. Urinary and plasma catecholamines and urinary catecholamine metabolites in pheochromocytoma: diagnostic value in 19 cases. Clin Chem 1994;40:250-6.

2. Sawka AM, Jaeschke R, Singh RJ, Young Jr WF. A comparison of biochemical tests for pheochromocytoma: measurement of fractionated plasma metanephrines compared with the combination of 24-hour urinary metanephrines and catecholamines. J Clin Endocrinol Metab 2003;88:553-8. 
3. Davidson DF. Urinary free catecholamines - diagnostic application of an HPLC technique to the investigation of neural crest tumours. Ann Clin Biochem 1987;24:494-9.

4. Goldstein DS, Graeme Eisenhofer G, Kopin IJ. Sources and significance of plasma levels of catechols and their metabolites in humans. J Pharmacol Exp Ther 2003;305:800-11.

5. Davidson DF. Phaeochromocytoma with normal catecholamines: the potential value of urinary free metadrenalines. Ann Clin Biochem 2002;39:557-66.

6. Reeves C, Roberts NB, Fairclough D, Higgins G, Reed P. The comparison of urinary free and total methylated catecholamines with free catecholamines in the laboratory assessment of catecholamine secreting tumours. Proc Association of Clinical Biochemists National Meeting, Birmingham, UK 2004:51 [abstract 23].

7. Sinclair D, Shenkin A, Lorimer AR. Normal catecholamine production in a patient with a paroxysmally secreting phaeochromocytoma. Ann Clin Biochem 1991;28:417-9.

8. Boyle JG, Davidson DF, Perry CG, Connell JM. Comparison of diagnostic accuracy of urinary free metanephrines, vanillyl mandelic acid, and catecholamines and plasma catecholamines for diagnosis of pheochromocytoma. J Clin Endocr Metab 2007;92:4602-8.

9. Davidson DF. Elevated urinary dopamine in adults and children. Ann Clin Biochem 2005;42:200-7.

10. Sargazi M, Smith ML, Worth RC, Roberts NB. A rare ganglioneuroblastoma secreting dopamine and the value of its measurement in diagnosis and prognosis. Ann Clin Biochem 2006;43:73-6.

11. Peaston RT, Ball S. Biochemical detection of phaeochromocytoma: why are we continuing to ignore the evidence? Ann Clin Biochem 2008;45:6-10.

12. Green DE, Richter DS. Adrenaline and adenochrome. Biochem J 1937;31:596-616.

13. Willemsen JJ, Ross HA, Lenders JW, Sweep FC. Stability of urinary fractionated metanephrines and catecholamines during collection, shipment, and storage of samples. Clin Chem 2007; 53:268-72.

14. Miki K, Sudo A. Effect of urine pH, storage time, and temperature on stability of catecholamines, cortisol, and creatinine. Clin Chem 1998;44:1759-62.

15. Boomsma F, Alberts G, van Eijk L, Man in't Veld AJ, Schalekamp MA. Optimal collection and storage conditions for catecholamine measurements in human plasma and urine. Clin Chem 1993;39:2503-8.

16. Green B, Cooper JD, Turnell DC. An automated method for the analysis of urinary free catecholamines using ASTED and high pressure liquid chromatography. Ann Clin Biochem 1989; 26:361-7.

17. Roberts NB, Dutton J, McClelland P, Bone JM. Urinary catecholamine excretion in relation to renal function. Ann Clin Biochem 1999;36:587-91.

18. Peaston RT, Weinkove C. Measurement of catecholamines and their metabolites. Ann Clin Biochem 2004;41:17-38.

19. Iu YP, Ho CS, Mak TW. Formate buffer as preservative for urinary free catecholamine measurement. Ann Clin Biochem 2004;41:39-42.

20. Gouarne C, Foury A, Duxclos M. Critical study of common conditions of storage of glucocorticoids and catecholamines in $24 \mathrm{hr}$ urine collected during resting and exercising conditions. Clin Chim Acta 2004;348:207-14.

21. Axelrod J. The metabolism of catecholamines in vivo and in vitro. Pharmacol Rev 1959;11:402-8.

22. Eisenhofer G, Kopin IJ, Goldstein DS. Catecholamine metabolism: a contemporary view with implications for physiology and medicine. Pharmacol Rev 2004;56:331-49.

23. Stott CA. Sulphonation and molecular action. Endocr Rev 2002;23:703-32.

24. Eisenhofer G, Huynh TT, Elkahloun A, Morris JC, Bratslavsky G, Linehan WM, et al. Differential expression of the regulated catecholamine secretory pathway in different hereditary forms of pheochromocytoma. Am J Physiol Endocrinol Metab 2008; 295:E1223-33.

25. Yu R, Nissen NN, Chopra P, Dhali D, Phillips E, Wei M. Diagnosis and treatment of phaechromocytoma in an academic hospital from 1997-2007. Am J Med 2009;122:85-95.

26. Sawka AM, Thabane L, Gafni A, Levine M, Young WF. Measurement of fractionated plasma metanephrines for exclusion of phaeochromocytoma; can specificity be improved by adjustment for age? BMC Endo Disord 2005;5:1-9.

27. Hickman PE, Leong M, Chang J, Wilson SR, McWhinney B. Plasma free metanephrines are superior to urine and plasma catecholamine metabolites for the investigation of phaeochromocytoma. Pathology 2009;41:173-7.

28. Dutton J, Hodgkinson AJ, Hutchinson G, Roberts NB. Evaluation of a new method for the analysis of free catecholamines in plasma using automated sample trace enrichment with dialysis and HPLC. Clin Chem 1999;45:394-9.

29. de Jong WH, Graham KS, van der Molen JC, Links TP, Morris MR, Ross HA, et al. Plasma free metanephrine measurement using automated online solid-phase extraction HPLC-tandem mass spectrometry. Clin Chem 2007;53:1684-93.

30. Pacak K, Eisenhofer G, Ilias I. Diagnosis of pheochromocytoma with special emphasis on MEN 2 syndrome. Hormones 2009;8:111-6. 